\title{
Flora da Usina São José, Igarassu, Estado de Pernambuco, Brasil: Cordiaceae e Heliotropiaceae
}

\author{
Camila Alcantara ${ }^{1,2}$ e (D) Rafael Louzada ${ }^{1}$
}

Recebido: 15.03.2019; aceito: 28.04 .2020

Como citar: Alcantara, C. \& Louzada, R. 2020. Flora da Usina São José, Igarassu, Estado de Pernambuco, Brasil: Cordiaceae e Heliotropiaceae. Hoehnea 47: e242019. http://dx.doi.org/10.1590/2236-8906-24/2019

RESUMO - (Flora da Usina São José, Igarassu, Estado de Pernambuco, Brasil: Cordiaceae e Heliotropiaceae). Cordiaceae e Heliotropiaceae juntas consistem em cerca de 850 espécies em sete gêneros e se distribuem principalmente nas regiões tropicais e subtropicais. No Brasil possuem ampla distribuição, sendo a região Nordeste uma das que se sobressai por englobar sete gêneros e cerca de 78 espécies, das quais 64 delas ocorrem no domínio da Mata Atlântica. Considerando essa representatividade, a fragmentação, a perda de diversidade e a carência de informações para a área, este trabalho inventariou a flora das famílias Cordiaceae e Heliotropiaceae em remanescentes florestais na Usina São José (USJ) no Estado de Pernambuco, Brasil. Foram registradas para a USJ, nove espécies, representando cinco gêneros, dos quais Cordia L. foi o gênero mais representativo, com quatro espécies. Descrições morfológicas que auxiliam no reconhecimento dos gêneros e espécies, chave de identificação, ilustrações comentários taxonômicos e de distribuição são apresentados.

Palavras-chave: Floresta Atlântica, Florística, Taxonomia

\begin{abstract}
Flora of the Usina São José, Igarassu, Pernambuco State, Brazil: Cordiaceae and Heliotropiaceae). Cordiaceae and Heliotropiaceae comprise ca. 850 species distributed and seven genera, and distributed mainly in the tropical, subtropical regions. In Brazil, they have wide distribution, mainly in the Northeastern region which has seven genera and about 78 species, of which 64 occur in the Atlantic Forest domain. Considering its representativeness, Atlantic forest fragmentation, loss of diversity and lack of information for this area, this paper inventoried the Cordiaceae and Heliotropiaceae family flora in forest remnants at the Usina São José (USJ), Pernambuco State, Brazil. Nine species belonging five genera were registered to USJ, of which Cordia L. with four species was the most representative genus. Morphological descriptions that help in the recognition of genera and species, a key of identification, illustrations, taxonomic comments and distributions are provided. Keywords: Atlantic Forest, Floristic, Taxonomy
\end{abstract}

\section{Introdução}

Boraginaceae consistia em quatro subfamílias: Boraginoideae, Cordioideae, Heliotropioideae e Ehretioideae (Gürke 1893). Nas últimas classificações da ordem Boraginales, foram realizadas revisões na sistemática da família, e essas subfamílias foram elevadas ao nível familiar (Böhler \& Hilger 1997, Gottschiling et al. 2001, APG IV 2016, BWG 2016).
Cordiaceae é representada pelos gêneros Cordia L. e Varronia P.Browne que compreende cerca de 400 espécies (Miller \& Gottschling 2007, BWG 2016), ) e possuem distribuição predominantemente tropical (Taroda 1984, Taroda \& Gibs 1986, BWG 2016) ocorrendo no Brasil, Peru e México (Gottschling et al. 2005). Já Heliotropiaceae, consiste em cinco gêneros: Euploca Nutt., Heliotropium L., Myriopus Small, Ixorhea Fenzl e Tournefortia L., que juntos somam cerca de 450 espécies (BWG 2016). Heliotropiaceae

1. Universidade Federal de Pernambuco, Laboratório de Morfo-Taxonomia Vegetal, Avenida Professor Moraes Rêgo s/n, 50670-901 Recife, PE, Brasil

2. Autor para correspondência: camila.bio@outlook.com 
possui ampla distribuição, porém com centro de diversidade na região Neotropical, ocorrendo principalmente na América do Sul (Hilger \& Diane 2003).

No Brasil, Cordiaceae está representada por 88 espécies (Cordia 55 spp., Varronia 33 spp.), sendo 49 delas endêmicas do Brasil (Flora do Brasil 2020, em construção. Heliotropiaceae, consiste em três gêneros e cerca de 46 espécies: Euploca (17 spp.), Heliotropium (10 spp.), Myriopus (oito spp.) e Tournefortia (11 spp.) (Flora do Brasil 2020, em construção). A região Nordeste se destaca pela diversidade de espécies das duas famílias, que juntas somam $78 \mathrm{spp}$. distribuídas principalmente na Mata Atlântica, em comparação, a região Sul apresenta 37 spp. (Flora do Brasil 2020, em construção). Essa riqueza é demonstrada nos levantamentos florísticos realizados nessa região como: Melo et al. 2009, Melo 2012, Melo \& Lemos 2008, Melo \& Sales 2004, Melo \& Sales 2005 e Melo \& Vieira 2017. De acordo com Flora do Brasil (2020, em construção), 64 espécies de Cordiaceae e Heliotropiaceae ocorrem na Mata Atlântica. A porção desse domínio ao norte do Rio São Francisco (centro de endemismo Pernambuco) é considerada uma das mais ameaçadas, já que restam apenas $5 \%$ da sua extensão original (Pôrto et al. 2005).

Tratamentos taxonômicos englobando as famílias (Boraginaceae sensu lato) no Brasil foram iniciados por Fresenius (1857) para a Flora Brasiliensis. No entanto, só recentemente relevantes contribuições relacionadas à sua taxonomia foram elaboradas no país e focados em floras locais e regionais. O presente trabalho tem como objetivo realizar o levantamento das espécies da família Cordiaceae e Heliotropiaceae ocorrentes na Usina São José (USJ), visando contribuir para o conhecimento da flora do Estado de Pernambuco, além de relatar aspectos morfológicos que auxiliem no reconhecimento dos gêneros e espécies, resultando em uma chave de identificação, ilustrações, comentários taxonômicos e de dados de distribuição.

\section{Material e Métodos}

A Usina São José (USJ), está localizada a cerca de $40 \mathrm{~km}$ ao norte da cidade do Recife, Estado de Pernambuco, Brasil (7040'21,25"- $\left.7^{\circ} 55^{\prime} 50,92^{\prime \prime} \mathrm{S}, 34^{\circ} 54^{\prime} 14,25^{\prime \prime}-35^{\circ} 05^{\prime} 21,08^{\prime \prime} \mathrm{W}\right)$, e possui uma área total de aproximadamente $280 \mathrm{~km}^{2}$. Sua maior parte encontra-se no município de Igarassu, mas abrange também os municípios Abreu e Lima, Araçoiaba, Goiana, Itapissuma e Itaquitinga (Melo et al. 2010). Situada na Floresta Atlântica, está entre as usinas que possuem os maiores remanescentes e maior extensão absoluta nesse domínio ao norte do São Francisco e possui vegetação de Floresta Estacional Semidecídual de Terras Baixas. Possui apenas uma área de proteção, conhecida como Refúgio da Vida Silvestre Mata da Usina São José, a qual possui 306 ha em bom estado de conservação e é protegida pela Lei Estadual $\mathrm{n}^{\circ} 9.989$ de 1987. A USJ possui 110 fragmentos de Floresta Atlântica com diferentes dimensões e formas (Trindade et al. 2008). Tendo como critério o tamanho dos fragmentos, foram selecionados seis para o desenvolvimento desse estudo: Macacos, Piedade, Zambana, Dedo de Deus, Chave e Santa Helena.

As coletas de material botânico fértil (com flores e/ou frutos) foram realizadas de acordo com as técnicas usuais em taxonomia vegetal (Mota et al. 2014), sendo posteriormente herborizadas conforme Mori et al. (1989), e inseridas nos herbários UFP, PEUFR e HST. A identificação do material e a terminologia utilizada para descrição foram baseadas em bibliografias especializadas (Harris \& Harris 2001) e consulta às coleções dos herbários visitados: UFP, IPA, PEUFR e HST (acrônimos seguindo Thiers 2019).

\section{Resultados e Discussão}

Nove espécies foram registradas para USJ, representando cinco gêneros, dos quais Cordia, com quatro espécies, foi o mais representativo. As espécies mais frequentes na área foram: Cordia nodosa Lam. e C. superba Cham., e as menos frequentes foram: $C$. sellowiana e $C$. toqueve Aubl. C. superba Cham. e Varronia multispicata (Cham.) Borhidi são endêmicas do Brasil. O fragmento Piedade foi o que apresentou a maior riqueza 2 com sete espécies, em sua maioria encontrada nas bordas de mata. Esse fragmento florestal é a única unidade de conservação da USJ na categoria Refúgio da Vida Silvestre, reforçando ainda mais a importância da sua preservação.

\section{Tratamento Taxonômico}

Cordiaceae e Heliotropiaceae

Árvores, arbustos, subarbustos, trepadeiras ou ervas. Folhas alternas ou subopostas, pecioladas, simples, venação broquidódroma, cladódroma ou eucamptódroma. Inflorescências terminais ou axilares, paniculadas, espiciformes ou escorpioides; flores bissexuadas, actinomorfas, diclamídeas, cálice 5-mero, campanulado a profundamente lobados, corola 5-mera, hipocrateriforme, campanulada ou infundibuliforme, alva, roxa ou amarela; estames 5, epipétalos, com filetes presentes ou ausentes; anteras livres ou coerentes entre si, introrsas ou extrorsas, deiscência longitudinal; ovário súpero; estigma clavado, espatulado, fusiforme, capitado ou cônico. Frutos secos ou carnosos, drupáceos ou esquizocárpicos constituídos por mericarpos (núculas) com cálices persistentes no fruto. 
Chave de identificação para espécies de Cordiaceae e Heliotropiaceae ocorrentes na Usina São José

1. Folhas com margens denteadas Varronia multispicata

1. Folhas com margens inteiras

2. Presença de domácias na base dos pecíolos Cordia nodosa

2. Ausência de domácias na base dos pecíolos

3. Lâmina foliar de consistência cartácea

4. Face abaxial da folha esparso-pubérula a glabrescente; flores $>2,5 \mathrm{~cm}$ compr. Cordia superba

4. Face abaxial da folha densamente pilosa e cinérea; flores $<2,5 \mathrm{~cm}$ compr. Myriopus candidulus

3. Lâmina foliar de consistência membranácea

5. Inflorescência paniculada

6. Face abaxial da lâmina foliar glabrescente a glabra; flores $0,9 \mathrm{~cm}$ compr.; ovário globoso Cordia sellowiana

6. Face abaxial da lâmina foliar pubescente; flores $0,4 \mathrm{~cm}$ compr.; ovário cilíndrico Cordia toqueve

5. Inflorescência escorpioide

7. Plantas com pecíolo alado

8. Face adaxial da lâmina foliar com superfície bulada; inflorescências axilares; esquizorcapo com 2 núculas ....... Heliotropium elongatum

8. Face adaxial da lâmina foliar com superficie lisa; inflorescências terminais; esquizorcarpo com 4 núculas Heliotropium indicum

7. Plantas com pecíolo não alado Tournefortia bicolor

1. Cordia nodosa Lam., Tabl. Encycl. 1: 422. 1791.

Figura 1 a-g

Árvores ou arbustos 1-4 m alt. Ramos híspidos. Folhas alternas e subopostas; pecíolos 0,5-1 cm compr., domácias na base; lâminas 7-32 × 4,7-19 cm, elípticas a obovadas, membranáceas, discolores, bases obtusas, ambas as faces glabras, híspidas nas nervuras principais e secundárias, venação broquidódroma, margens inteiras, ápices acuminados. Inflorescências terminais, paniculadas, laxas; pedúnculos ca. $1 \mathrm{~cm}$ compr., híspidos; flores ca. $1 \mathrm{~cm}$ compr., sésseis; cálices ca. $4 \mathrm{~mm}$ compr., campanulados, híspidos, ápice dos lacínios agudos; corolas alvas, ca. 1 cm compr., campanuladas, fauces creme, lobos ca. $5 \mathrm{~mm}$ compr., ovais; filetes ca. $8 \mathrm{~mm}$ compr., tricomas na base.; anteras ca. $2 \mathrm{~mm}$ compr., oblongas; ovários ca. $2 \mathrm{~mm}$ compr., subgloboso, tricomas híspidos no ápice, disco nectarífero ausente; estiletes ca. $8 \mathrm{~mm}$ compr., bipartido; estigmas 4 , ca. $0,6 \mathrm{~mm}$ compr., espatulados, anel estigmático ausente. Frutos drupa, oval, imaturos verdes, maduros amarelos.

Material examinado: Brasil. Pernambuco: Igarassu, Usina São José, Mata dos Macacos, 21.II.2017, fl., C.A. Pereira et al. 67 (HST, PEUFR, UFP); Ibid., 28.III.2003, fr., G.L. Bezerra \& A. Melquíades 172 (UFP); Mata do Pezinho, 01.X.2009, fr., D. Marcelino \& M.A. Chagas 10 (UFP); ibid., 01.IV.2008, est., J.S. Gomes et al. 207 (UFP); Mata de Piedade, 22.II.2017, fl., C.A. Pereira et al. 69 (HST, PEUFR, UFP); Mata de Santa Helena, 28.I.2009, fr., E. Pessoa \& T. Arruda 26 (UFP); Mata da Zambana, 26.X.2016, fl. e fr., C.A. Pereira et al.56 (HST, PEUFR, UFP); Ibid., 12.VI.2008, est., M.A.M. Silva 47 (UFP); Ibid., 21.III.2007, est., N.A. Albuquerque \& J.S. Marques 229 (UFP).

Segundo Miller et al. (1998) Cordia nodosa distribuise na Colômbia, Peru, Bolívia, Equador, Guiana Francesa, Guiana Inglesa, Venezuela e Brasil. No Brasil, ocorre nas regiões Norte, Nordeste e Centro-oeste, nos domínios da Amazônia, Cerrado e Mata Atlântica (Flora do Brasil 2020, em construção). É uma espécie frequente na área, sendo encontrada em bordas e interior dos fragmentos. Se diferencia das demais espécies ocorrentes na área de estudo, por possuir domácias na base dos pecíolos.

2. Cordia sellowiana Cham., Linnaea 4: 479. 1829. Figura 1 h-l

Árvores 3-10 m alt. Ramos tomentosos. Folhas alternas; pecíolo $0,5-1,3 \mathrm{~cm}$ compr., domácias ausentes; lâminas 10,4-16,2 × 3,5-8,5 cm, elípticas ou lanceoladas, membranáceas, concolores, base aguda a obtusa, face adaxial glabra a estrigosa, face abaxial glabrescente até glabra, venação cladódroma, margens inteiras, ápices acuminados. 
Inflorescências terminais, paniculadas, laxas; pedúnculos 1,7-4,6 cm compr, estrigosos a glabros; flores ca. 0,9 cm compr., sésseis; cálices ca. 4,3 mm compr., campanulados, estrigosos, ápices dos lacínios triangulares; corolas alvas, ca. $7 \mathrm{~mm}$ compr., campanuladas, fauces alvas, lobos ca. 4 mm compr., oblongos, ápices arredondados; filetes ca. 4 $\mathrm{mm}$ compr., tricomas na base; anteras ca. 1,4 $\mathrm{mm}$ compr., oblongo-ovais; ovários ca. $2 \mathrm{~mm}$ compr., globoso, glabro, disco nectarífero ausente; estiletes ca. $3 \mathrm{~mm}$ compr., bipartido, estigma 4 , ca. $0,4 \mathrm{~mm}$ compr., fusiformes, anel estigmático ausente. Frutos não observados.

Material examinado: Brasil. Pernambuco: Igarassu, Usina São José, Mata de Piedade, 22.IV.2008, est., N.A. Albuquerque et al. 484 (IPA); Ibid., 03.XII.2009, est., J.A.N. Souza et al.342 (UFP).

Material adicional examinado: Brasil. Pernambuco: Lagoa do Ouro, Reserva Biológica Federal da Pedra Talhada, 26.XI.2014, fl., L. Nusbaurner \& A. Cailliau 4440 (UFP); Pesqueira, Serra do Ororobá, 26.X.1995, fl., M. Correia 387 (UFP).

Cordia sellowiana é endêmica do Brasil, ocorre nas regiões Norte, Nordeste, Centro-oeste, Sudeste, Sul e nos domínios da Amazônia, Caatinga, Cerrado e Mata Atlântica (Flora do Brasil 2020, em construção). É uma espécie pouco frequente na área, encontrada nas bordas dos fragmentos. Se diferencia das demais espécies do gênero por possuir o ápice dos lobos da corola arredondados e ovário globoso.

\section{Cordia superba Cham., Linnaea 4: 474-475. 1829.}

Figura1 m-q

Árvores ou arbustos 2-4 m alt. Ramos escabros. Folhas alternas; pecíolos 0,4-2,8 cm de compr., domácias ausentes; lâminas 8-24 × 3,6-15,8 cm, elípticas a obovadas, cartáceas, discolores, base obtusa, face adaxial glabrescente a escabra, face abaxial esparso-pubérula a glabrescente, venação cladódroma, margens inteiras, ápices cuneados. Inflorescências terminais, paniculadas, laxas; pedúnculos 3-7 cm compr.; flores 2,5-5 cm compr., pedicelos 0,1-1 mm compr.; cálices ca. $1,3 \mathrm{~cm}$ compr., campanulados, glabros; corolas alvas ou amarelas, 2,5-5 cm compr., infundibuliforme, fauces amarelas, lobos ca. $1 \mathrm{~cm}$ compr., subtriangulares, ápices subagudos; filetes ca. $8 \mathrm{~mm}$ compr., tricomas na base; anteras ca. $3 \mathrm{~mm}$ compr., oblongas; ovários ca. $3 \mathrm{~mm}$ compr., subglobosos, glabros, disco nectarífero ausente; estiletes ca. $2,3 \mathrm{~cm}$ compr., bipartido, estigma-4, ca. 1,8 mm compr., clavados, anel estigmático ausente. Frutos drupas, ovoides, imaturos verdes, maduros alvos.

Material examinado: BrasiL. PernambUCo: Igarassu, Usina São José, Mata de BR, 09.VI.2008, fr., P.G.A. Mendes et al. 81 (UFP); Mata da Chave, 08.VIII.2008, est., T.N.F. Gomes 45 (UFP); Mata Dedo de Deus, fl., 26.X.2016, C.A.
Pereira et al. 57 (HST, PEUFR,UFP); Mata dos Macacos, 10.IV.2007, est., A. Alves-Araújo et al. 614 (UFP); Ibid., 09.XII.2002, est., I.M.M Sá e Silva et al. 9 (UFP); Mata de Piedade, 11.VII.2007, est., A.L.A. Lima 630 (UFP); Ibid., 22.II.2017, fl., C.A. Pereira et al. 70 (HST, PEUFR,UFP); Ibid., 17.XII.2009, fl., J.A.N. Souza et al. 583 (UFP); Ibid., 18.XII.2008, fl., J.S. Gomes \& M.A. Chagas 292 (UFP); Mata da Zambana, 29.X.2007, fr., A. Melo \& N. Albuquerque 188 (UFP); Ibid., 26.X.2016, fr., C.A. Pereira et al. 54 (HST, PEUFR,UFP); Ibid., 22.III.2007, est., D. Araújo et al. 557 (UFP); Ibid., 16.III.2008, fl., M.A.M. Silva et al. 25 (UFP).

Cordia superba é endêmica do Brasil e ocorre nas regiões Norte, Nordeste, Centro-oeste, Sudeste e Sul, nos domínios da Amazônia, Caatinga, Cerrado e Mata Atlântica (Flora do Brasil 2020, em construção). É uma espécie frequente na área de estudo, sendo encontrada em bordas e interior dos fragmentos. Se diferencia das demais espécies da área por possuir flores maiores que $2,5 \mathrm{~cm}$, enquanto as demais possuem flores menores que $1 \mathrm{~cm}$.

4. Cordia toqueve Aubl., Hist. Pl. Guiane 1: 228-230. 1775. Figura r-v

Árvores ou arbustos ca. $7 \mathrm{~m}$ alt. Ramos pubescentes. Folhas alternas; pecíolos 0,7-2,8 cm de compr., domácias ausentes; lâminas 8-24 × 5,6-12,5 cm, elípticas ou oval-elipticas, membranáceas, concolores, base obtusa, face adaxial escabra, face abaxial pubescente, venação cladódroma, margens inteiras, ápices cuneados. Inflorescências terminais, paniculadas, laxas; pedúnculos $3,6 \mathrm{~cm}$ compr.; flores ca. $0,4 \mathrm{~cm}$ compr., sésseis; cálices ca. 3,2 mm compr., campanulados, verdes, pubescentes; corolas alvas, ca. $3,8 \mathrm{~mm}$ compr., campanuladas, lobos ca. $1,2 \mathrm{~mm}$ compr., oblongos, ápices truncados; filetes 1-1,2 mm compr., sem tricomas na base; anteras oblongas, ca. $0,5 \mathrm{~mm}$ compr.; ovários ca. 2 mm compr., cilíndricos, glabros, disco nectarífero ausente; estiletes ca. $2 \mathrm{~mm}$ compr., bipartidos, estigmas-4, ca. 0,3 mm compr., fusiformes, anel estigmático ausente. Frutos não observados.

Material examinado: Brasil. Pernambuco: Igarassu, Mata de Piedade, Mata de Piedade, bf., 09.V.2007, A. Melo et al. 140 (UFP); Engenho Campinas, 25.X.2007, bf., L.M. Nascimento \& G. Batista 724 (UFP).

Material adicional examinado: Brasil. Pernambuco: São Lourenço da Mata, 11.II.2004, fl., M.S. Sobrinho 512 (UFP).

Cordia toqueve é endêmica do Brasil e ocorre nas regiões Norte, Nordeste e Sudeste, nos domínios da Amazônia, Caatinga, Cerrado e Mata Atlântica (Flora do Brasil 2020, em construção). É uma espécie pouco frequente na área de estudo, sendo encontrada nas bordas dos fragmentos. Se diferencia das demais espécies do gênero por possuir o ápice dos lobos da corola truncados e ovário cilíndrico. 


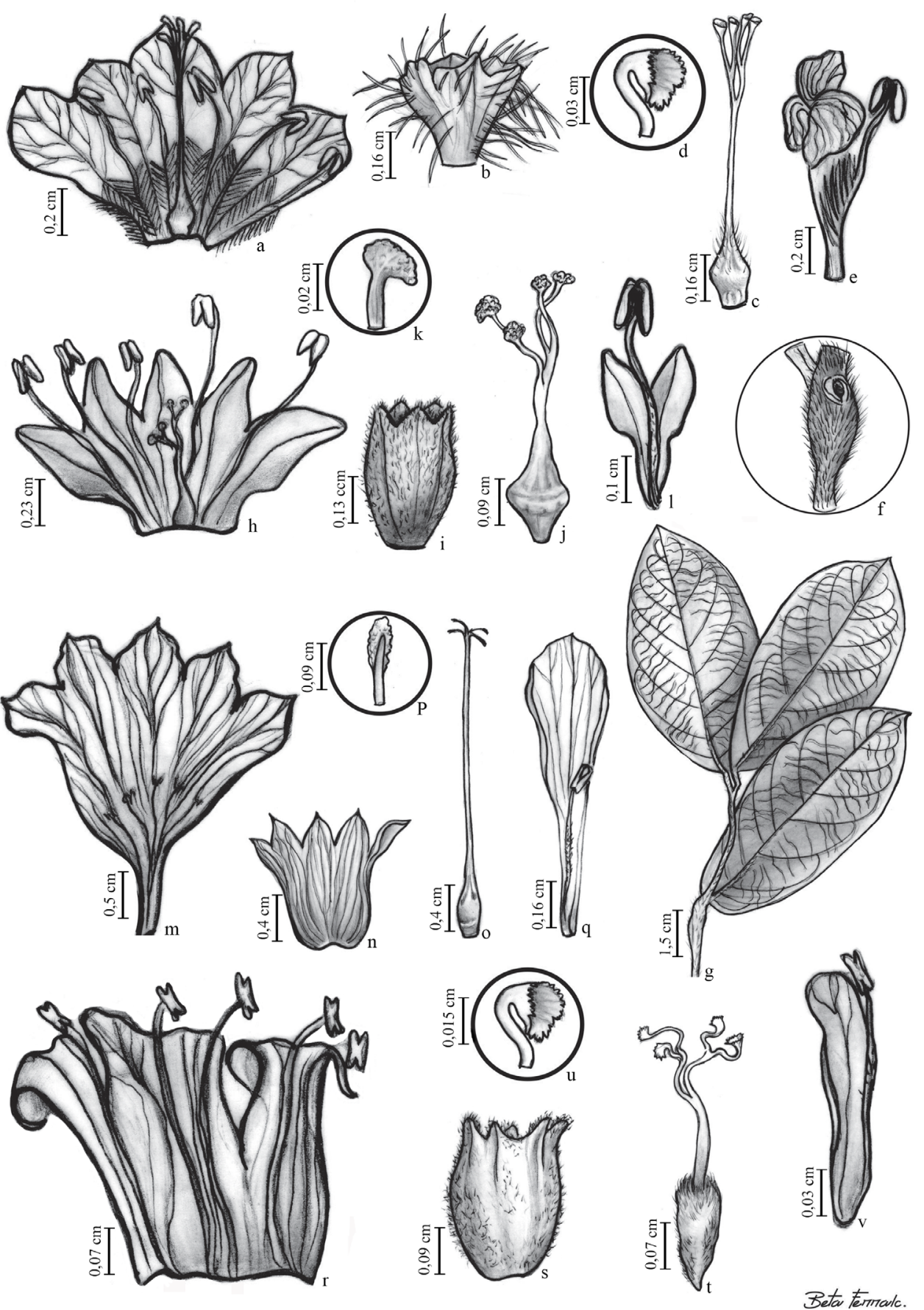

Figura 1. a-g Cordia nodosa Lam. a. flor em secção longitudinal. b. detalhe do formato do cálice. c. gineceu. d. detalhe do formato do estigma. e. detalhe da forma dos lobos da corola e dos estames. f. detalhe da domácia. g. ramo. h-1 Cordia sellowiana Cham. h. flor em secção longitudinal. i. detalhe do formato do cálice. j. gineceu. k. detalhe do formato do estigma. 1. detalhe da forma dos lobos da corola e dos estames. m-q. Cordia superba Cham. m. flor em secção longitudinal. n. detalhe do formato do cálice. o. gineceu. p. detalhe do formato do estigma. q. detalhe da forma dos lobos da corola e dos estames. r-v. Cordia toqueve Aubl. r. flor em secção longitudinal. s. detalhe do formato do cálice. t. gineceu. u. detalhe do formato do estigma. v. detalhe da forma dos lobos da corola e dos estames. (a-g. M.F.A.Lucena 387; h-1. M.Correia 387; m-q. A.A. Araújo 614; r-v. M.S.Sobrinho 512)

Figure 1. a-g. Cordia nodosa Lam.- a. flower in longitudinal section. b. calyx shape detail. c. gynoeceum. d. stigma format detail. e. detail of the shape of the corolla and stamens wolves. f. detail domatia. g. branch. h-l Cordia sellowiana Cham. h. flower in longitudinal section. i. calyx shape detail. j. gynoeceum. k. stigma format detail. 1. detail of the shape of the corolla and stamens wolves. m-q. Cordia superba Cham. m. flower in longitudinal section. n. calyx shape detail. o. gynoeceum. p. stigma format detail. q. detail of the shape of the corolla and stamens wolves. r-v- Cordia toqueve Aubl. r. flower in longitudinal section. s. calyx shape detail. t. gynoeceum. u. stigma format detail. v. detail of the shape of the corolla and stamens wolves. (a-g. M.F.A.Lucena 387; h-1. M.Correia 387; m-q. A.A. Araújo 614; r-v. M.S.Sobrinho 512). 
5. Heliotropium elongatum (Lehm.) I.M. Johnst., Nat. Pflanzenfam., 4(3a): 96. 1893.

Figura 2 a-c

Ervas ou subarbustos, ca. $60 \mathrm{~cm}$ de alt.. Ramos hirsutos. Folhas alternas e subopostas; pecíolos $0,6-4,5 \mathrm{~cm}$ de compr., alado, domácias ausentes; lâminas 2,5-4,5 × 2,4-5,3 cm, ovais, membranáceas, concolores, bases truncadas ou assimétricas, face adaxial bulada, glabrescente ou escabra, face abaxial pubescente, venação eucamptódroma, margens inteiras, ápices acuminados ou agudos. Inflorescências axilares, escorpióides, laxas; pedúnculos 1,5-3 cm compr., pubescentes; flores ca. 0,6 cm compr., sésseis; cálices 1,5-2 $\mathrm{mm}$ compr., profundamente lobado, lacínios lanceolados, tricomas aciculiformes; corolas alvas ou lilases, fauces amarelas, $6 \mathrm{~mm}$ compr., hipocrateriformes, pubescentes, lobos ca. 0,9 mm compr., orbiculares; estames sésseis; anteras oblongas, ca. $1 \mathrm{~mm}$ compr.; ovários ca. $0,4 \mathrm{~mm}$ compr., globosos, glabros, discos nectaríferos ca. 0.1 $\mathrm{mm}$ compr; estiletes ca. $0,2 \mathrm{~mm}$ compr., estigmas ca. 0,3 mm compr., clavados, anel estigmático ausente. Frutos esquizocarpos, núculas -2 justapostas, 4,0-5,0 mm compr.

Material examinado: Brasil. PeRnAmbUCo: Igarassu, Usina São José, Mata de Piedade, 05.XI.2008, fl. e fr., K.C. Araújo 14 (UFP); Mata de Santa Helena, 28.I.2009, fl. e fr., E. Pessoa \& T. Arruda 30 (UFP); Mata da Usina São José, 20.X.1999, fl. e fr., A. Silva (IPA 61.591); Mata de Zambana, 25.I.2017, fr. e fl., C.A. Pereira et al. 60 (HST, PEUFR, UFP).

Ocorre na Bolívia, Brasil, Uruguai, Argentina e Paraguai (Johnston 1928). No Brasil ocorre nas regiões Norte, Nordeste, Centro-Oeste, Sudeste e Sul. Ocorre nos domínios da Amazônia, Caatinga, Cerrado, Mata Atlântica e Pampa (Melo \& Semir 2008, Flora do Brasil 2020, em construção). É uma espécie pouco frequente na área de estudo, sendo encontrada nas bordas dos fragmentos. Se assemelha a Heliotropium indicum, porém se diferencia desta por possuir a face adaxial das folhas buladas vs. lisa, e um esquizorcapo com 2 núculas justapostas $v s .4$ núculas agrupadas 2 a 2 .

6. Heliotropium indicum L., Sp. Pl. 1: 130. 1753. Figura $2 \mathrm{~d}-\mathrm{f}$

Erva, ou subarbusto, ca. $60 \mathrm{~cm}$ de alt. Ramos escabros. Folhas alternas e subopostas; pecíolos 1,5-4,5 cm compr., alado, domácias ausentes; lâminas 2,5-6 × 2,2-53 cm, ovalelípticas a oval-deltóides, membranáceas, concolores, bases truncadas, face adaxial lisa, ambas as faces pubescentes, venação eucamptódroma, margens inteiras ou erosas, ápices acuminados. Inflorescências terminais, escorpióides, laxas; pedúnculos 1,8-3,2 cm compr.; flores 0,4-0,5 cm compr., sésseis; cálices ca. $2 \mathrm{~mm}$ compr., lacínios lanceolados, tricomas aciculiformes; corolas alvas ou roxas, fauces amarelas, 4,0-5,0 mm compr., hipocrateriformes, pubescentes; estames sésseis; anteras oblongo-ovais, ca. $0,4 \mathrm{~mm}$ compr., ápices agudos; ovários ca. $0,3 \mathrm{~mm}$ compr., globosos, glabros, discos nectaríferos ca. $0,1 \mathrm{~mm}$ compr; estiletes ca. 0,2 mm compr., estigmas ca. $0,2 \mathrm{~mm}$ compr., capitados, anel estigmático ausente. Frutos esquizocarpos, mitriformes, núculas-4, ca. 3,0 mm compr., agrupadas 2 a 2 .

Material examinado: Brasil. Pernambuco: Igarassu, Usina São José, Mata dos Macacos, 21.II.2017, fl., C.A. Pereira et al. 68 (HST, PEUFR, UFP); Mata de Piedade, 25.I.2017, fr. e fl., C.A. Pereira et al. 59 (HST, PEUFR, UFP); Ibid., 19.XII.2007, fl. e fr., D. Araújo \& A. Alves Araújo 516 (UFP); Ibid., 19.XII.2007, fl. e fr., D. Araújo \& A. Alves-Araújo 518 (UFP).

Distribui-se nas regiões tropicais do globo (Miller, 1988). No Brasil, Heliotropium indicum ocorre nas regiões Norte, Nordeste, Centro-oeste, Sudeste e Sul (Melo \& Semir 2008), nos domínios da Amazônia, Caatinga, Cerrado, Mata Atlântica, Pampa e Pantanal (Flora do Brasil 2020, em construção). É uma espécie pouco frequente na área de estudo sendo encontrada nas bordas dos fragmentos. Se assemelha a Heliotropium elogatum, e sua distinção foi discutida sob os comentários dessa espécie.

7. Myriopus candidulus (Miers) Feuillet, J. Bot. Res. Inst. Texas, 2(1): 264. 2008.

Figura $2 \mathrm{i}-\mathrm{k}$

Arbustos ca. $2 \mathrm{~m}$ alt., ou trepadeiras. Ramos pubescentes. Folhas alternas; pecíolos 0,5-4 cm de compr., domácias ausentes; lâminas 2-8 × 1-3 cm, elípticas ou obovadas, cartáceas, discolores, bases agudas a obtusas, face adaxial tomentosa, face abaxial densamente pilosa e cinérea, venação broquidódroma, margens inteiras, ápices agudos a acuminados. Inflorescências terminais, paniculadas, laxas; pedúnculos 1-2 cm.; flores 0,3-0,6 cm compr., pedicelos ca. 2 $\mathrm{mm}$ compr.; cálices ca. $4 \mathrm{~mm}$ compr., vilosos, profundamente lobados, lacínios elípticos; corolas alvas, amarelas, verdes ou roxas, ca. $6 \mathrm{~mm}$ compr., infundibuliformes, vilosas, lobos ca. $1 \mathrm{~mm}$ compr., filiformes; estames sesséis; anteras ca. 0,8 mm compr., ovóides, coniventes com ápices adpressos entre si; ovários ca. $0,8 \mathrm{~mm}$ compr., cilíndricos, glabros, disco nectarífero ausente; estiletes ca. $0,7 \mathrm{~mm}$ compr., estigmas ca. $0,8 \mathrm{~mm}$ compr., com anel estigmático evidente, ápice cônico, triangular e alongado. Frutos drupas com 4 pirênios, imaturos verdes, maduros alvos.

Material examinado: Brasil. Pernambuco: Igarassu, Usina São José, Mata do Pezinho, 05.IX.2007, fr., A. Alves-Araújo et al. 247 (UFP); Mata da Piedade, 19.XII.2007, fl., $D$. Araújo \& A. Alves-Araújo 532 (UFP); Ibid., 02.I.2010, J. D. García G. 1413 (UFP); Mata da Zambana, 17.VII.2007, fl. e fr., A. Alves-Araújo \& D. Araújo 407 (UFP); Ibid., 14.II.2008, fl., A. Alves-Araújo \& J.S. Marques 846 (UFP).

Myriopus candidulus ocorre na Venezuela, Guiana e no Brasil (Jhonst 1930, Funk et al. 2007, Hokche 2008). No Brasil ocorre nas regiões Nordeste e Sudeste, nos domínios da Amazônia, Caatinga, Cerrado, Campo Rupestre e Mata atlântica (Flora do Brasil 2020, em construção, Melo \& 

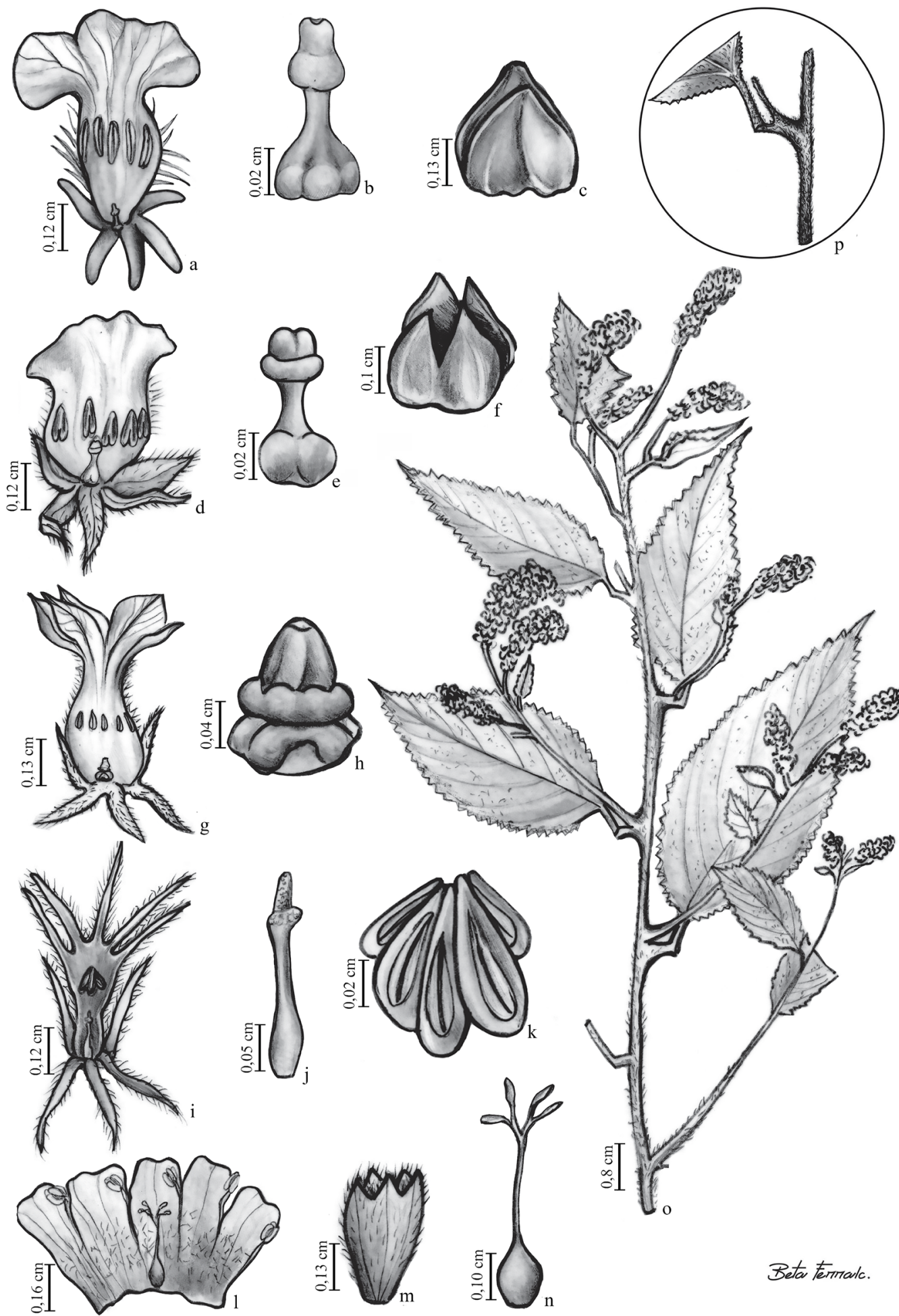

Beta terrioulc.

Figura 2. a-c. Heliotropium elongatum (Lehm.) I.M. Johnst. a. flor em secção longitudinal. b. gineceu. c. esquizocarpo com 2 núculas. d-f. Heliotropium indicum L. d. flor em secção longitudinal. e. gineceu. f. fruto. g-h. Tournefortia bicolor Sw. g. flor em secção longitudinal. h. gineceu. i-k. Myriopus candidulus (Miers) Feuillet. i. flor em secção longitudinal. j. gineceu. k. detalhe das anteras. 1-p. Varronia multispicata (Cham.) Borhidi. 1. flor em secção longitudinal. m. cálice. n. gineceu. o. ramo. p. detalhe do pecíolo com articulação suprabasal. (a-c. T.Arruda 30; d-f. D.Araújo 518; g-h. E.pessoa 121; i-k. K.C.Araújo 10; 1-p. E.Pessoa 36).

Figure 2. a-c. Heliotropium elongatum (Lehm.) I.M. Johnst. a. flower in longitudinal section. b. gynoeceum. c. fruit. d-f. Heliotropium indicum L. d. flower in longitudinal section. e. gynoeceum. f. fruit. g-h. Tournefortia bicolor Sw. g. flower in longitudinal section. h. gynoeceum. i-k. Myriopus candidulus (Miers) Feuillet. i. flower in longitudinal section. j. gynoeceum. k. Detail of anthers. 1-p. Varronia multispicata (Cham.) Borhidi. l. flower in longitudinal section. m. calyx. n. gynoeceum. o. branch. p. detail of the petiole with suprabasal joint. (a-c. T.Arruda 30; d-f. D.Araújo 518; g-h. E.pessoa 121; i-k. K.C.Araújo 10; 1-p. E.Pessoa 36). 
Vieira 2017). É uma espécie pouco frequente na área de estudo, sendo encontrada nas bordas dos fragmentos. Se diferencia das demais espécies da área por possuir ramos densamente pilosos e cinéreos, e uma drupa com 4 pirênios.

8. Tournefortia bicolor Sw., Prodr. 40. 1788.

Figura $2 \mathrm{~g}-\mathrm{h}$

Árvores ca. 4-16 m de alt., arbustos ca. 2-40 m de alt., ou trepadeiras. Ramos pubescentes. Folhas alternas; pecíolos 1-4 cm de compr., domácias ausentes; lâminas 5-14,5 × 2-7 cm, elípticas, cartáceas, discolores, base obtusa, ambas as faces glabrescentes, venação broquidódroma, margem inteira, ápice acuminado. Inflorescências terminais, escorpióides, laxas; pedúnculos 1-4 cm compr., pubescentes; flores ca. 0,6 cm compr., sésseis; cálices ca. 2 $\mathrm{mm}$ compr., pubescentes, profundamente lobados, lacínios lanceolados, ápices agudos; corolas alvas, ca. $6 \mathrm{~mm}$ compr., infundibuliformes, pubescentes com tricomas ferrugíneos, lobos ca. $3 \mathrm{~mm}$ compr., elípticos; estames sésseis; anteras ca. $1 \mathrm{~mm}$ compr., lanceoladas; ovários ca. $0,5 \mathrm{~mm}$ compr., ovóides, glabros, disco nectarífero ausente; estigmas sésseis, ca. $0,9 \mathrm{~mm}$ compr., com anel estigmático evidente, ápice cônico, triangular. Frutos drupas com 2 pirênios, verde, glabro.

Material examinado: Brasil. PernambUCo. Igarassu, Usina São José, Mata da Chave, 24.XI.2009, fl., E. Pessoa \& J.A.N. Souza 132 (UFP); Ibid., 24.XI.2009, fl., J.A.N. Souza et al. 557 (UFP); Mata de Pezinho, 10.IV.2007, fl., A. AlvesAraújo et al. 574 (UFP); Mata da Piedade, 19.XII.2007, fr., A. Alves-Araújo \& D. Araújo 709 (UFP); Ibid., 24.I.2008, fr., A. Alves-Araújo et al. 805 (UFP); Ibid., 28.VIII.2007, fl., D. Araújo 451 (UFP); Ibid., 14.X.2003, fl. e fr., I.M.M. Sáe Silva \& S.G. Freire 196 (UFP); Ibid., 14.X.2009, fl. e fr., J. D. García 1347 (UFP); Ibid., 05.XI.2008, fl., K.C. Araújo 10 (UFP); Ibid., 06.XI.2008, fl., K.C. Araújo 16 (UFP).

Tournefortia bicolor distribui-se do México a América Central, Guiana e Paraguai (Funk et al. 2007, Johnston 1930, Miller 1988,). No Brasil ocorre nas regiões Norte, Nordeste, Centro-oeste, Sudeste e Sul, e nos domínios da Amazônia, Cerrado e Mata Atlântica (Flora do Brasil 2020, em construção). É uma espécie pouco frequente na área de estudo sendo encontrada nas bordas dos fragmentos. Se diferencia das demais espécies da área por possuir os lobos da corola filiformes e drupa com 2 pirênios.

9. Varronia multispicata (Cham.) Borhidi, Acta Bot. Hung. 34(3-4): 392. 1988.

Figura $21-p$

Arbustos 1,7-3 m alt. Ramos pubescentes. Folhas alternas; pecíolos com articulação suprabasal, domácias ausentes; lâminas 6,7-10 × 3-5,2 cm, lanceoladas a ovadas, cartáceas, discolores, bases obtusas, face adaxial escabra, face abaxial pubescente, venação broquidódroma, margens denteadas, ápices agudos. Inflorescências axilares, espiciformes, congestas; pedúnculos $0,7-4 \mathrm{~cm}$ compr., escabros; flores ca. $0,5 \mathrm{~cm}$ compr., sésseis; cálices ca. $4 \mathrm{~mm}$ compr., pubescentes, campanulados, lacínios triangulares; corolas alvas, fauces alvas, 5-6 mm compr., campanuladas, glabras, lobos ca. $2 \mathrm{~mm}$ compr., ápices subtruncados; filetes ca. 1,2 mm compr., tricomas na base; anteras ca. $0,6 \mathrm{~mm}$ compr., oblongas. Ovários ca. 1,3 mm compr., globosos, glabros, disco nectarífero ausente; estiletes ca. $3,2 \mathrm{~mm}$ compr., bipartido, estigmas ca. $0,7 \mathrm{~mm}$ compr., clavados, anel estigmático ausente. Frutos drupas, arredondados, imaturos verdes, maduros vermelhos.

Material examinado: Brasil. PeRnambuco: Igarassu, Usina São José, Mata do Pezinho, 23.V.2003, fr., A. Alves-Araújo 289 (UFP); Ibid., 14.II.2008, fl., L.M. Nascimento \& G. Batista 704 (UFP); Mata de Santa Helena, 28.I.2009, fl., E. Pessoa \& T. Arruda 36 (UFP); Mata da Usina São José, 12.III.2003, fl., G.J. Bezerra \& A. Melquiades 137 (UFP).

Varronia multispicata é endêmica do Brasil e ocorre nas regiões Norte, Nordeste, Centro-oeste e Sudeste, nos domínios da Amazônia, Caatinga, Cerrado e Mata Attântica (Flora do Brasil 2020, em construção). É uma espécie pouco frequente na área, sendo encontrada nas bordas dos fragmentos. Se diferencia das demais espécies da área de estudo por possuir pecíolo com articulação suprabasal, margens das folhas denteadas e frutos vermelhos na maturação.

\section{Agradecimentos}

À Usina São José, o apoio logístico para as coletas. Ao CNPq U.S. National Science Foundation, Velux Stiftung, Beneficia Foundation e BMBF, pela bolsa concedida ao primeiro Autor. Aos Curadores dos Herbários visitados. À Beta Ferralc, pelas ilustrações e à equipe do Laboratório de Morfo-Taxonomia Vegetal, pelo apoio.

\section{Literatura citada}

APG IV-Angiosperm Phylogeny Group. 2016. An update of the Angiosperm Phylogeny Group classification for the orders and families of flowering plants: APG IV. Botanical journal of the Linnean Society, 181: 1-20.

Böhle, U.R. \& Hilger, H.H. 1997. Chloroplast DNA systematics of "Boraginaceae" and related families: a goodbye to the old familiar concept of 5 subfamilies. Scr. Bot. Belg., 15: 30.

BWG- Boraginales Working Group. 2016. Familial classification of the Boraginales. Taxon, 63: 502-522.

Flora do Brasil 2020 em construção. Jardim Botânico do Rio de Janeiro. Disponível em < http://floradobrasil.jbrj. gov.br/ > (acesso em 15-XI-2019)

Fresenius, G. 1857. Cordiaceae, Heliotropieae et Borragineae. In Flora Brasiliensis (C.F.P. Martius, A.G. Eichler \& I. Urban, eds.). W. Munchen, Leipzig, 9: 1-60. 
Funk, T.H., Hollowell, V., Berry, P.E., Kelloff, C. \& Alexander, S. 2007. Checklist of the Plants of the Guiana Shield (Venezuela; Amazonas, Bolivar, Delta Amacuro; Guyana, Surinam, French Guiana). Contribuition From the United States National Herbarium, 55: 1-584.

Gottschling, M., Hilger, H.H., Wolf, M. \& Diane, N. 2001. Secondary Structure of the ITS1 Transcript and its Application in a Reconstruction of the Phylogeny of Boraginales. Plant Biology, 3: 629-636.

Gottschling, M., Miller, J.S. Weigend, M. \& Hilger, H. 2005. Congruence of a Phylogeny of Cordiaceae (Boraginales) Inferred from ITS1 Sequence Data with Morphology, Ecology, and Biogeography. Annals of the Missouri Botanical Garden, 92(3): 425-437.

Gürke, M. 1893. Boraginaceae. In Die natürlichen Pflanzenfamilien (A. Engler \&K. Prantl, eds.). V.W. Engelmann, Leipzig, (15): 49-96.

Harris, J.G. \& Harris, M.W. 2001. Plant identification terminology: an illustrated glossary. Spring Lake Publishing.

Hilger, H.H. \& Diane, N. 2003. A systematic analysis of Heliotropiaceae (Boraginales) based on trnL and ITS1 sequence data. Botanische Jahrbücher Systematic, 125: 19-51.

Johnston, I.M. 1930. Observations on the species of Cordia and Tournefortia known from Brazil, Paraguay, Uruguay and Argentina. Contributions from the Gray Herbarium of Harvard University, 92: 3-89.

Johnston, I.M. 1928. The South American species of Heliotropium. Contributions from the Gray Herbarium of Harvard University, 81: 3-73.

Melo, A., Alves-Araújo, A. \& Alves, M. 2010. Burmanniaceae e Gentianaceae da Usina São José, Igarassu, Pernambuco. Rodriguésia, 61: 431-440.

Melo, J.I.M. 2012. Flora do Parque Nacional do Catimbau, Pernambuco, Brasil: Boraginaceae sensu lato. Revista Biotemas, 25 (4): 109-120.

Melo, J.I.M., Gomes, R.L. \& Ferraz, E.M.N. 2009. Boraginaceae A. Juss. sensu lato em uma floresta estacional de terras baixas em Pernambuco, Brasil. Revista Caatinga, 22(4): 179-186.

Melo, J.I.M. \& Lemos, R.P.L. 2008. Sinopse taxonômica de Boraginaceae sensu latoA. Juss. no Estado de Alagoas, Brasil. Acta Botanica Brasilica, 22(3): 701710.

Melo, J.I.M., Paulino, R.C. \& Silva, F.V. 2007. Chave ilustrada para os gêneros deBoraginaceae sensu lato nativos do Brasil. Revista Caatinga, 20(3): 172-180.
Melo, J.I.M. \& Sales, M.F. 2004. Heliotropium L. (Boraginaceae - Heliotropioideae) de Pernambuco, Nordeste do Brasil. Rodriguésia, 55 (84): 65-87.

Melo, J.I.M. \& Sales, M.F. 2005. Boraginaceae A. Juss. na região de Xingó: Alagoas e Sergipe. Hoehnea 32: 369-380.

Melo, J.I.M. \& Semir, J. 2008. Taxonomia do gênero Heliotropium L. (Heliotropiaceae) no Brasil. Acta Botânica Brasilica, 22(3): 754-770.

Melo, J.I.M. \& Vieira, D.D. 2017. Flora da Reserva Biológica de Guaribas, PB, Brasil: Boraginaceae. Hoehnea, 44(3): 407-414.

Miller, J.S. 1988. A revised treatment of Boraginaceae for Panama. Annals of the Missouri Botanical Garden, 75: 456-521.

Miller, J.S., Gaviria, J., Gómez, R. \& Rodríguez, G. 1998. Boraginaceae. In: Flora of the Venezuelan Guayana. In P.E. Berry, B.K. Holst \& K. Yatskievych (eds.). Saint Louis, Missouri Botanical Garden, pp. 527-547.

Miller, J.S. \& Gottschling, M. 2007. Generic Classification in the Cordiaceae (Boraginales): Resurrection of the Genus Varronia P. Br. Taxon, 56(1): 163-169.

Mori, S.A., Mattos-Silva, L.A., Lisboa, G. \& Coradin, L. 1989. Manual de manejo do herbário fanerogâmico. Centro de Pesquisas do Cacau, Ilhéus.

Mota, N.F., Paula, L.F. \& Viana, P.L. 2014. Guia Prático de Métodos de Campo para Estudos de Flora. Bocaina Biologia da Conservação. $2^{\mathrm{a}}$ ed. Belo Horizonte.

Pôrto, K., Almeida-Cortez, J.S. \& Tabarelli, M. 2005. Diversidade biológica e conservação da floresta Atlântica ao norte do Rio São Francisco. Brasília: Coleção Biodiversidade. Ministério do Meio Ambiente.

Taroda, N. 1984. Taxonomic studies on Brazilian species of Cordia (Boraginaceae). PhD Thesis, University of Saint Andrews, Saint Andrews.

Taroda, N. \& Gibbs, P.E. 1986. A revision of the Brazilian species of Cordia subgenus Varronia (Boraginaceae). Notes from the Royal Botanical Gardens of Edinburgh, 44: 105-140.

Thiers, B. 2019. [continuously update]. Index Herbariorum: A global directory of public herbaria and associated staff. New York Botanical Garden's Virtual Herbarium. Disponível em $<$ http://sweetgum.nybg.org/science/ih/> (acesso em 20-IV-2019.

Trindade, M.B., Lins-e-Silva, A.C.B., Silva, H.P., Figueira, S.B. \& Schessl, M. 2008.Fragmentation of the Atlantic rainforest in the northern coastal region of Pernambuco, Brazil: Recent changes and implications for conservation. Bioremediation, Biodiversity and Bioavailability, 2: 5-13. 